\title{
Request Strategies: A Contrastive Study Between Yemeni EFL and Malay ESL Secondary School Students in Malaysia
}

\author{
Amr Abdullatif Yassin ${ }^{1,2} \&$ Norizan Abdul Razak ${ }^{1}$ \\ ${ }^{1}$ Faculty of Social Sciences and Humanities, Universiti Kebangsaan Malaysia, Bangi, Selangor, Malaysia. \\ ${ }^{2}$ Centre of Languages and Translation, Ibb University, Ibb, Yemen. \\ Correspondence: Amr Abdullatif Yassin, Centre of Languages and Translation, Ibb University, Yemen. Tel: \\ 60-11-3734-6177. E-mail: amryassin84@gmail.com
}

\author{
Received: September 1, $2018 \quad$ Accepted: October 18, $2018 \quad$ Online Published: November 29, 2018 \\ doi:10.5539/ass.v14n12p29 \\ URL: https://doi.org/10.5539/ass.v14n12p29
}

\begin{abstract}
The aim of this study was to investigate the types of request strategies employed by Yemeni and Malay secondary school students in English language. It also aimed at investigating the influence of social power and social distance on the students' choice of request strategies. The data was collected through a discourse completion test (DCT) and the analysis used both Blum-Kulk's et al. (1989) Cross-Cultural Speech Act Realization Patterns (CCSARP), and Scollon and Scollon's (1995) politeness system. The findings of the study showed that both groups often use non-conventionally indirect request strategies by means of query preparatory. The analysis revealed that both groups do not take into consideration the social power and the social distance between the interlocutors because they always use the same strategies with any person. The students have this sociopragmatic knowledge in their mother tongue; however, both groups are not sensitive to the social power and social distance existing between the interlocutors as they lack the sociopragmatic knowledge in the target language. Moreover, the students almost use the same strategies even though they have different cultural backgrounds, and this might be attributed to their assimilation in the school learning environment which is a positive indicator for conductive learning environment.
\end{abstract}

Keywords: Politeness request strategies, Yemeni EFL, Malay ESL, English Language, secondary school students

\section{Introduction}

Learning a second of foreign language requires the learner to pay attention to the process of using the language in real communicative situations because every culture has its own codes. Learners cannot master the target language without having language competence and this is the aim of language learning and teaching (Daskalovska, Ivanovska, Kusevska, \& Ulanska, 2016). Richards (1992) as cited in Marazita, (2009) defined linguistic competence as the ability not only to apply the grammatical rules of a language in order to form grammatically correct sentences but also to know when and where to use these sentences and to whom. Learners of any language should pay attention to the social and cultural aspect of the target language or the pragmatic ability so that they can communicate with the others by using accurate and appropriate methods (Tabar \& Malek, 2013; Khalib \& Tayeh, 2014).

One of the significant topics which have attracted the attention of the researchers lately is the speech act of request which has been investigated by many researchers in different places (Umar, 2004; Félix-Brasdefer, 2005; Pinto \& Raschio, 2007; Alaoui, 2011; Aubed, 2012). Learners of English or any other target language should take into consideration the speech act of requests because they are "face-threatening acts" (FTAs) (Brown \& Levinson, 1987). People use different indirect strategies in order to save the self-image which the speaker or the hearer have and try to minimize the face threat in order to carry out the process of communication smoothly (Félix-Brasdefer, 2005). Request acts might threaten the face of the speaker or the hearer if the social distance, power relations and cultural values of the others are not considered because the speech act of request is different from one culture to another (Al-Marrni et al., 2010; Tawalbeh et al., 2012; Aubed, 2012).

Sattar et al. (2009) argued that studies that investigate the cross-cultural communication is of great asset to the instructors and the students to improve their cross-cultural understanding which have a positive influence on the 
process of second language acquisition.

There are few studies that have investigated the speech act of request among Yemeni students who are studying in Yemen such as the two studies conducted by Al-Marrani et al. (2010a), (2010b), and Alfattah et al. (2009). However, the influence which a new culture might have on the speech acts of request when the learner studies in a foreign country or a multi-ethnic society has not yet been investigated among Yemeni students. Also, it is not clear if the investigation of the act of request among Yemeni students in Malaysia will provide different results from the previous studies due to their intermingling with the other students who have different cultural backgrounds. So, additional studies on the Yemeni students who are studying in a multi-cultural environment is needed in order to highlight if there is any influence for the new culture on the speech acts of request.

Moreover, there are many Malaysian students who study in the international Arabic schools in Malaysia. Malaysian students in these schools study Arabic courses, and are mostly taught by Arabic teachers, and they intermingle with Arab students since they spend most of their time in the schools. Therefore, the aim of this paper is to compare the polite request strategies employed by Yemeni EFL and Malay ESL secondary school students in the international Arabic schools in Malaysia and find out the effect of the power, social distance and degree of imposition on the choice of request strategies.

In addition, there are few studies which have investigated request strategies among teenagers, and there is a need to investigate this issue among secondary school students and their use of request strategies during the interaction as this will help to provide them with the needed feedback so that they can improve their pragmatic competence and be able to communicate with others more effectively (Elsayed, 2014; Balci, 2009).

When a speaker makes a request, he is not merely uttering words as $\mathrm{s} / \mathrm{he}$ is performing an act which requires understanding of the characteristics, conditions and the effect which a request have in a second or a foreign language. Without understanding the skills of the speech acts of request, the communication might not be completed successfully. Actually, non-native speakers might not be able to deal with different situations and adapt their speech according to the context of the communication which might result in the breakdown of the communication due the lack of the pragmatic competence (Marazita, 2009; Jalilifar, 2009; Lee, 2011).

When the speaker requests another person, he tells him/her to do something for the benefit of the speaker. The request becomes more complicated when you request a person using a foreign language. Making request needs better understanding of the cultural and linguistic elements of request when communicating with people who have different backgrounds in order to communicate with others without losing face and fulfil the speaker's goal of making the request. This makes the studies that compare between the request strategies in different cultures important to provide a better understanding on how people in different cultures use different forms of request strategies to make the speech act of request meaningful (Byon, 2004; Al-Kahtani, 2005; Kahraman \& Akkuş, 2007; Youssef, 2012).

Requesting others in the target language might threaten the face of the speaker or the listener as every culture has its own forms of requesting which might differ from those used in the other cultures (Al-Marrni et al., 2010a; 2010b; Tawalbeh et al., 2012). In Yemeni culture, people tend to use imperatives or direct requests and such requests are not considered as impolite as it is considered in the other cultures (Al-Marrani et al., 2010a). Investigating this issue among Yemeni secondary school students in the international schools in Malaysia might have a different result from the studies conducted by Al-Marrani et al. (2010) and Alfattah and Ravindranath (2009) since the participants are studying the curriculum in English and have experienced a new culture. Most importantly, comparing the strategies used by Yemeni and Malay students will help to shed light upon the differences between the two cultures. There is no study that has investigated the differences between Yemeni and Malay students which make such studies crucial to provide a better understanding of how strategies of request are used cross-culturally in order to mitigate the request in the target language.

\subsection{Research Objectives}

This study aims to investigate the following objectives:

1. To compare polite request strategies employed by Yemeni EFL and Malay ESL students inside the classroom in an international school in Malaysia.

2. To investigate how the power and social distance have an effect on the choice of the request strategies among the two groups.

\subsection{Research Questions}

This study aims to answer the following questions: 
1. What are the request strategies employed by Yemeni EFL and Malay ESL secondary school students inside the classroom?

2. How do the factors of power and social distance have an effect on the request strategies choice in the two groups?

\section{Literature Review}

This section will discuss the theoretical back ground which includes Blum-Kulka's et al. (1989) model Cross-Cultural Speech Act Realization Patterns (CCSARP) and Scollon and Scollon's (1995) request strategies framework as well as the previous studies.

\subsection{Theoretical Background}

Politeness is the actual realization of good manners and it reflects the etiquette which a person has when dealing with others. There is a relationship between the indirectness of request and politeness as it is better for the person to use indirect requests to show politeness to the listener when asking him to do anything. Leech (1983:108) as cited in Tabar, M. S. (2012) states that "the more indirect an illocution is, the more diminished and tentative its force tends to be".

Blum-Kulka's et al. (1989) model Cross-Cultural Speech Act Realization Patterns (CCSARP) divides the request strategies into direct, conventionally indirect and non-conventionally indirect. Five of these heads are considered direct: mood derivable, explicit performatives, hedged performatives, obligation statement and want statement. Two of these heads are considered conventionally indirect: suggestory formula and query preparatory. Also, two are considered non-conventionally indirect: strong hints and mild hints.

The following table provides the degrees of politeness from the less polite to the most polite with some examples for each type. The examples are quoted from Blum-Kulka et al. (1989).

\begin{tabular}{|c|c|c|}
\hline \multirow{5}{*}{ Direct strategies } & Mode derivable & 'Please, leave me alone.' \\
\hline & Explicit performatives & 'I am asking you to clean up the mess.' \\
\hline & Hedged performatives & $\begin{array}{l}\text { 'I would like to ask you to give your presentation a } \\
\text { week earlier than scheduled.' }\end{array}$ \\
\hline & Obligation statement & 'You will have to move that car.' \\
\hline & Want statement & 'I really want you to stop bothering me.' \\
\hline \multirow{2}{*}{$\begin{array}{l}\text { Conventionally indirect } \\
\text { strategies }\end{array}$} & Suggestory formula & 'How about cleaning up tonight.' \\
\hline & Query preparatory & 'Could you clean up the kitchen, please?' \\
\hline \multirow{2}{*}{$\begin{array}{l}\text { Non-conventionally } \\
\text { indirect strategies }\end{array}$} & Strong hint & 'You have left the kitchen in a right mess.' \\
\hline & Mild hint & 'I am a nun.' \\
\hline
\end{tabular}

In addition, Scollon and Scollon's (1995) framework divides the polite request strategies into three systems depending on the social power which the interlocutors have and the social distance between the interlocutors. The first system is the deference politeness system in which no one of the interlocutors have power over the other (-Power) but with a social distance relationship (+Distance). As a result, the interlocutors try to avoid losing face by using appropriate expressions that mitigate the request. The second is the solidarity politeness system in which the interlocutors have equal social position (-Power) and close relationship (-Distance). In this system, the interlocutors use involvement strategies to express reciprocity and to claim common point of view or to express the feeling of closeness. The third system is the hierarchy politeness system in which one of the interlocutors has a power over the other (+Power). In this system, one of the interlocutors is in the superordinate position (+Power) whereas the other is in a subordinate position (-Power). The interlocutors who are in the superordinate position use involvement strategies while those who are in the subordinate position use independent strategies to show respect and to minimize the threat of losing face.

\subsection{Previous Studies}

There are many studies that have investigated the speech act of request in different parts of the world which showed that people use different strategies when requesting the others depending on the social distance and cultural values. Although the majority of the studies have focused on university students and neglected school students, the school students especially in secondary school have a good command in suing request strategies and there might not be differences between university students and secondary school students. Ervin-Trip (1977: 175) as cited in Nisa et al. (2014) argued that children in the age of three can use different forms of request such as using imperatives, permission and models. In the age of four, children can use want/need statements in order 
to request the others to do something. By the age nine and ten, the children can use forms like 'can you' and 'could you'. They also try to mitigate the request by using words like 'please'. The accumulative knowledge which the children gain during the interaction and the study in the school leads them to master the strategies of request at the age of eleven Gordon and Ervin-Tripp (1984) as cited in Nisa et al. (2014).

Berna Balci (2009) made a study to compare the use of request strategies and apologies between Turkish and American teenagers. The data was collected from 20 Turkish students and 20 American students whose age is between 14-15. The data was collected by using Discourse Completion Tests. The data was analysed by using CCSARP (Cross-Cultural Speech Act Realization Project) developed by Blum-Kulka (1989). The results showed that there are some differences between the native and non-native speakers of English. Thus, native speakers prefer to use preparatory, want statement, hedging performatives and mood derivable head acts when the request the others while non-native Turkish speakers prefer to use preparatory, mood derivable and strong hint head acts when requesting the others. According to the researcher, the American students use appropriate request strategies whereas Turkish students do not use appropriate request strategies.

Similarly, Elsayed (2014) conducted a study to compare request strategies used by adolescence and the aim was to compare the request strategies employed by adolescence native-speakers of English and adolescence non-native speakers of English. The participants in this study are 30 native speakers of English from the USA, UK and Canada which form the first group. The second group are 30 non-native speakers of English from UAE, Egypt, Pakistan, Malaysia, German, Philippine, India, and Iran. The age of the participants is between 13 and 15 and the two groups completed a Discourse Completion Test which analysed after that depending of Blum-Kulka's (1989) model. The study revealed that there is a difference between the two groups in terms of using request strategies as non-native speakers prefer to use direct strategies while the native speakers prefer to use indirect request strategies.

Al-Marrani et al. (2010a) have investigated the polite request strategies that are used by Yemeni university students when males interact with males and males interact with females. The participants of this study were 168 male students and 168 female students undergraduate. The participants study in different disciplines in Sana'a University. The data was collected from Sana'a University which located in the north of Yemen, and it was better to collect the data from different cities since the habits and the traditions are somewhat different in the south and the middle regions from the north of Yemen. The theory used in this paper is the model created by Blum-Kulka et al. (1989). The data was analysed by using SPSS. The study revealed that males use direct request strategies when they interact with males but use indirect strategies when they interact with females.

Al-Marrani et al. (2010b) aimed to investigate the request strategies used by Yemeni students. It investigates the requests used by females when interacting with females and the request strategies when females interact with males. This study is considered the second phase of the previous study conducted by Al-Marrani et al. (2010a). Thus, the previous study investigated the request strategies used by males, but this study investigates the request strategies used by females. The data was collected by using Discourse Completion Test (DCT). And then the data was decoded by using CCSARP (Cross Cultural Speech Act Realization Project) developed by Blum-Kulka et al. (1989). The study showed that request strategies are different from one culture to another. In Yemen, for example, the use of imperative form is not considered that impolite as it is considered in English or in the other cultures. Moreover, the analysis revealed that there is a tendency to use indirect strategies in cross gender interaction more than the same gender interaction.

There are studies that aimed to highlight the differences between the languages in the speech act of request because what seems to be impolite in one culture might not consider impolite in another culture. Also, some languages are richer in the expressions that are used to perform the act of request than the other languages. Aubed (2012) aimed to compare the request strategies in Arabic and English. This study highlights the differences between the two languages and proved that the request strategies in Arabic and English are not identical. This can be helpful for the researchers in this field to understand that there are many request strategies differences between languages. Also, the study reveals that Arabic language is richer than English language in the forms of making requests as one sentence can be translated in different forms.

Moreover, there are many studies that have compared between the act of request performed by people belonging to different cultures and highlighted the differences between the two cultures. Youssef (2012) carried out a study to investigate the similarities and the differences in the request strategies used by Libyans and Malaysians students studying at USM. The data for this study was collected from different existing materials which can be found in other researches, books and website. However, it was better for the researcher to collect the data for the research and compare the results with those available in other resources. Also, the researcher did not highlight 
the theoretical framework which will be used in the study. Non-specialized reader might not be able to get the model which this research is using to analyse the data. The results of the study show that both Malaysians and Libyans use direct request strategies in natural conversations more than role-plays. Malaysians most often use indirect head acts while Libyans use both indirect and direct head acts. Also, the Libyans use honorific words more than the Malaysian students. In role-play, the Malaysians pay attention to the request strategies when they are observed more than the Libyan students do.

Also, Tawalbeh and Al-Oqaily (2012) study aimed at investigating the differences in indirectness and politeness between Saudi and American native speakers. The data was gathered from 30 undergraduate Saudi and American students who have responded to discourse completion test made of twelve situations. The study used Blum-Kulka et al.'s (1989) model to analyse the data. The result of the study supports the previous studies in the point that request differs from culture to another. Besides, the study revealed that the most preferred strategy used by the American students is the conventional indirectness even when they are addressing their friend or inferior persons while the Saudi students prefer to use conventional indirectness when they request people who are superior to them, but they use direct strategies when interacting with close friends. However, the participants are males and females and it was better to highlight if there are differences between American and Saudi females students because females in America have the same rights as males whereas the Arabic countries are closed and traditional so females do not have the same rights as males. This might lead to some differences in the request strategies employed by the Saudi females when requesting the others.

According to the studies presented above, it is clear that the speech act of request has different forms of realization and it is different from one culture to another. Students of a second or a foreign language might not be aware of the differences between cultures which might result in the breakdown of the communication. Besides, speech act of request is not identical in all the cultures and some cultures might be richer than the other cultures in the formation of the request.

\section{Methodology}

\subsection{Participants}

The participants in this study are 20 Yemeni secondary school students and 20 Malay secondary school students studying in an international Arabic school in Kuala Lumpur. The age of the participants is between 16-19 years old, and the students in this age have acquired request strategies according to Gordon and Ervin-Tripp (1984).

\subsection{Procedures and Data Analysis}

The data is collected through a Discourse Completion Test (DCT) as this method proved to be a good method for collecting the students' responses and it has been used in may papers (Alfattah \& Ravindranath, 2009; Codreanu \& Debu, 2011; Tawalbeh \& Al-Oqaily, 2012).

In discourse completion test, the students are given certain situations and a description for these situations. The students have to engage in these situations and write their responses (Codreanu \& Debu, 2011). In this paper, the students will be given six hypothesized situations which have been adapted from (Alfattah \& Ravindranath, 2009). The students will be asked to complete every situation and fill in what they say as a response to every situation.

The students write their responses to the contexts in English language and then the data is analysed depending on the head act classification given by Blum-Kulka et al. (1989) known as CCSARP which divides the head act of request strategies into direct, conventionally indirect and non-conventionally indirect strategies. Moreover, the situations will be divided according to Scollon and Scollon (1995) into three systems depending on the social power and social distance: hierarchal politeness system, deference politeness system and solidarity politeness system.

Table 1. Combination of explanatory variables

\begin{tabular}{llll}
\hline Situation 1 & $\mathrm{~S}>\mathrm{H}$ & $-\mathrm{SD}$ & Low \\
Situation 2 & $\mathrm{~S}>\mathrm{H}$ & $+\mathrm{SD}$ & High \\
Situation 3 & $\mathrm{~S}<\mathrm{H}$ & $+\mathrm{SD}$ & Low \\
Situation 4 & $\mathrm{~S}<\mathrm{H}$ & $-\mathrm{SD}$ & Low \\
Situation 5 & $\mathrm{~S}=\mathrm{H}$ & $-\mathrm{SD}$ & High \\
Situation 6 & $\mathrm{~S}=\mathrm{H}$ & $-\mathrm{SD}$ & High \\
\hline
\end{tabular}

\section{Results and Discussion}

The discussion will divide the six situations into three groups. The first group is situation 1 and situation, the 
second group is situation 3 and situation 4, and the third group is situation 5 and situation 6 . In each group the distribution of the request strategies will be investigated.

\section{Situation 1 and situation 2:}

Situation 1: You want your younger brother to bring some vegetable from the near-by grocery. What would you say?

Situation 2: You are a teacher in a school. One of your students has brought his new laptop. You want to ask him to use it for an hour. What would you say?

Table 2 and figure 1 below give the request strategies used by Yemeni and Malay students in situation 1 and situation 2. The results give the use of request strategies at each level of directness which are direct strategies, conventionally indirect strategies, and non-conventionally indirect strategies.

Table 2. shows the frequency of request strategies used by Yemeni and Malay students in situation 1 and situation 2

\begin{tabular}{|c|c|c|c|c|c|c|}
\hline \multirow{4}{*}{ Situation } & \multicolumn{4}{|c|}{ Direct Strategies } & \multicolumn{2}{|c|}{ Conventionally Indirect Strategies } \\
\hline & \multicolumn{3}{|c|}{ Yemeni Students } & \multirow{3}{*}{$\begin{array}{c}\begin{array}{c}\text { Malay } \\
\text { Students }\end{array} \\
\text { Mood } \\
\text { Derivable }\end{array}$} & \multirow{3}{*}{$\begin{array}{c}\text { Yemeni Students } \\
\text { Query } \\
\text { Preparatory }\end{array}$} & \multirow{3}{*}{$\begin{array}{c}\text { Malay Students } \\
\text { Query } \\
\text { Preparatory }\end{array}$} \\
\hline & Mood & Want & Hedged & & & \\
\hline & Derivable & Statement & Performatives & & & \\
\hline S1 & $\% 10$ & & & $10 \%$ & $90 \%$ & $90 \%$ \\
\hline S2 & $10 \%$ & $20 \%$ & $10 \%$ & $10 \%$ & $60 \%$ & $90 \%$ \\
\hline
\end{tabular}

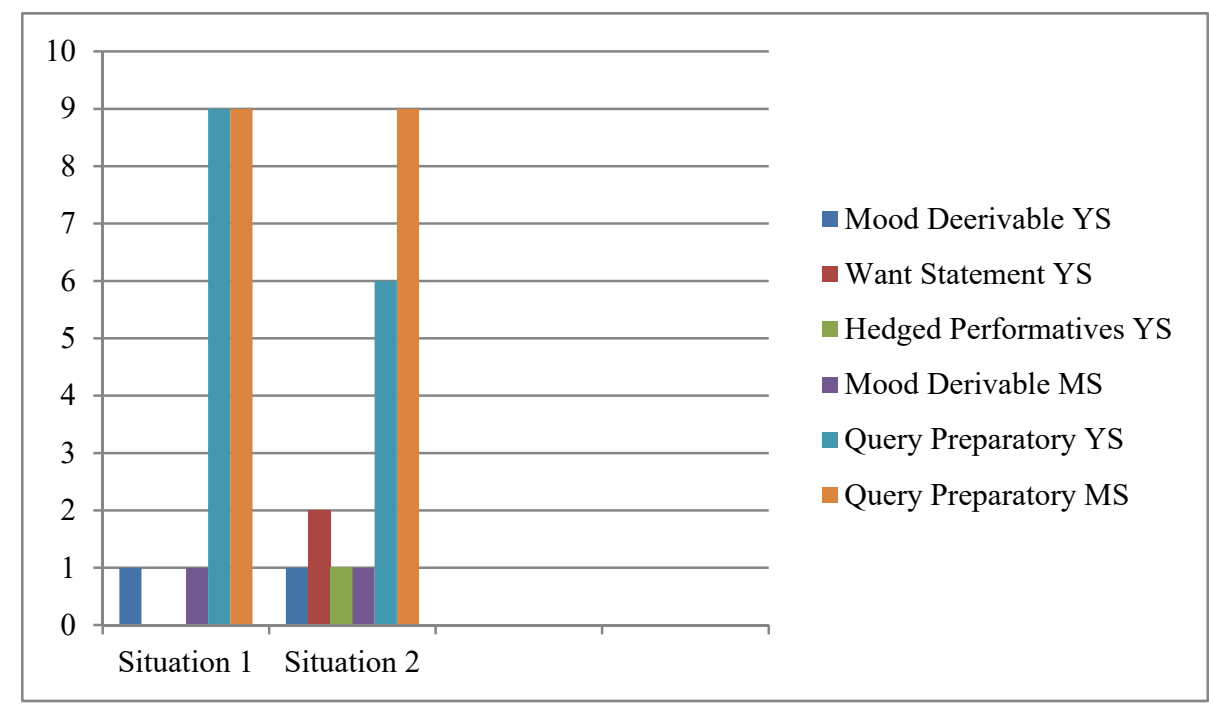

Figure 1. Distribution of request strategies used by Yemeni and Malay Students in situation 1 and 2

The head act which is most used in the process of interaction by both Yemeni and Malay secondary school students is query preparatory. In the first situation, Yemeni students used $90 \%$ query preparatory and $10 \% \operatorname{mood}$ derivable. Similarly, Malay students used $90 \%$ query preparatory and $10 \%$ mood derivable.

In the second situation, the result is somewhat different as the Yemeni students used more direct strategies which scores $40 \%$, and $60 \%$ conventionally indirect strategies. Yemeni students used $10 \%$ mood derivable, $20 \%$ want statement, 10 hedged performatives, and $60 \%$ query preparatory. On the other side, the Malay students used $90 \%$ query preparatory strategies, and only $10 \%$ mood derivable strategies.

Examples of direct strategies (mood derivable, and want statement) used by Yemeni students:

I want to use your computer for an hour.

I need you laptop for an hour.

Please brother, take this list and buy the vegetables.

Examples of direct strategies (mood derivable) used by Malay students: 
Get me some vegetables form the grocery store.

Give me your laptop for one hour, please.

Examples of indirect strategies (query preparatory) used by Yemeni students:

May I borrow your laptop?

Mohammed, can you get some vegetables from the near-by grocery shop?

Would you go down to the store and get me some vegetables?

Examples of indirect strategies (query preparatory) used by Malay students:

Hi bro, would you mind bringing some vegetables from the grocery store?

Hello Jack, would you care to lend me your laptop so that I can use it for an hour?

Brother, can you buy some vegetables from the near-by grocery store please?

According to Scollon and Scollon (1995), the first two situations come under hierarchal politeness system. In this system, the relationship between the interlocutors is unequal as the speaker is in a higher position (+Power) and the hearer is in a lower position (-Power). Here interlocutors might use involvement or direct strategies to show their solidarity with the hearer and it goes with the cultural norms since the requester is in a higher position while the requestee is in a lower position.

In these two situations, the result of the analysis shows that Yemeni students use direct strategies to show their solidarity with the hearer due to the existence of the difference between the speaker and the hearer. Al-Marrani (2010a) (2010b) explained that when Yemeni students request the others in the Arabic language, they used involvement strategies when the requester is in a higher position. However, Yemeni students in this study used conventionally indirect strategies more than the direct strategies which might be due to the influence of the target language on process of requesting. Students have studied in English language how to use polite request strategies so the students here used what they have studied and try to be polite even if there is power difference between the interlocutors. Also, this shows that the students might not be sensitive to the socio-pragmatic knowledge in the target language.

Malay students rarely used direct strategies in these two situations and it is clear that Yemeni students have used direct strategies more than the Malay students. Malay students have used conventionally indirect strategies when they request the others even if there is a power difference between the interlocutors. The influence of English language is there as the students tend to use the politeness request strategies they have studied in the classroom, but their responses show that they lack socio-pragmatic knowledge in the target language.

From the examples shown above, it is clear that the Yemeni and Malay students used expressions such as "Brother" and "hi bro". Also, they used names to address the hearer such as "Mohammed" and "Hello Jack". Such expressions are used to soften the request and to show camaraderie between the interlocutors. What is noticed here is that both Yemeni and Malay students used these expressions when they use direct and indirect strategies which shows that the students try to be polite as much as possible when they use the target language.

Moreover, Yemeni and Malay students used semi-formulaic expressions such as "can", "could", and "may" when they make requests in the target language in order to mitigate the request and show respect to the requestee.

Table 2 and Figure 1 show that Yemeni used direct strategies more than the Malay students, but still the number of the indirect request strategies used by Yemeni students is much more than the direct request strategies. Besides, both groups try to be polite as much as possible when they make requests in English language by using appropriate expressions and softeners to show a sense of request to the hearer.

\section{Situation 3 and situation 4}

Situation 3: You are a student and you want to request your teacher to lend you his book to do your assignment. What would you say?

Situation 4: You have got scholarship and you want your teacher who taught you in the school to write you a recommendation letter. What would you say?

Table 3 and Figure 2 show the use of request strategies employed by Yemeni and Malay students at every level of directness: direct request strategies, conventionally indirect request strategies, and non-conventionally indirect request strategies. 
Table 3. shows the frequency of request strategies used by Yemeni and Malay students in situation 3 and situation 4

\begin{tabular}{cccccc}
\hline \multirow{2}{*}{ Situation } & \multicolumn{2}{c}{ Direct Strategies } & \multicolumn{2}{c}{ Conventionally Indirect Strategies } \\
\cline { 2 - 6 } & \multicolumn{2}{c}{ Yemeni Students } & Malay Students & Yemeni Students & Malay Students \\
\cline { 2 - 6 } & Mood Derivable & Want Statement & Hedged Performatives & Query Preparatory & Query Preparatory \\
\hline S3 & $10 \%$ & & $90 \%$ & $100 \%$ \\
S4 & $10 \%$ & $10 \%$ & $10 \%$ & $80 \%$ & $90 \%$ \\
\hline
\end{tabular}

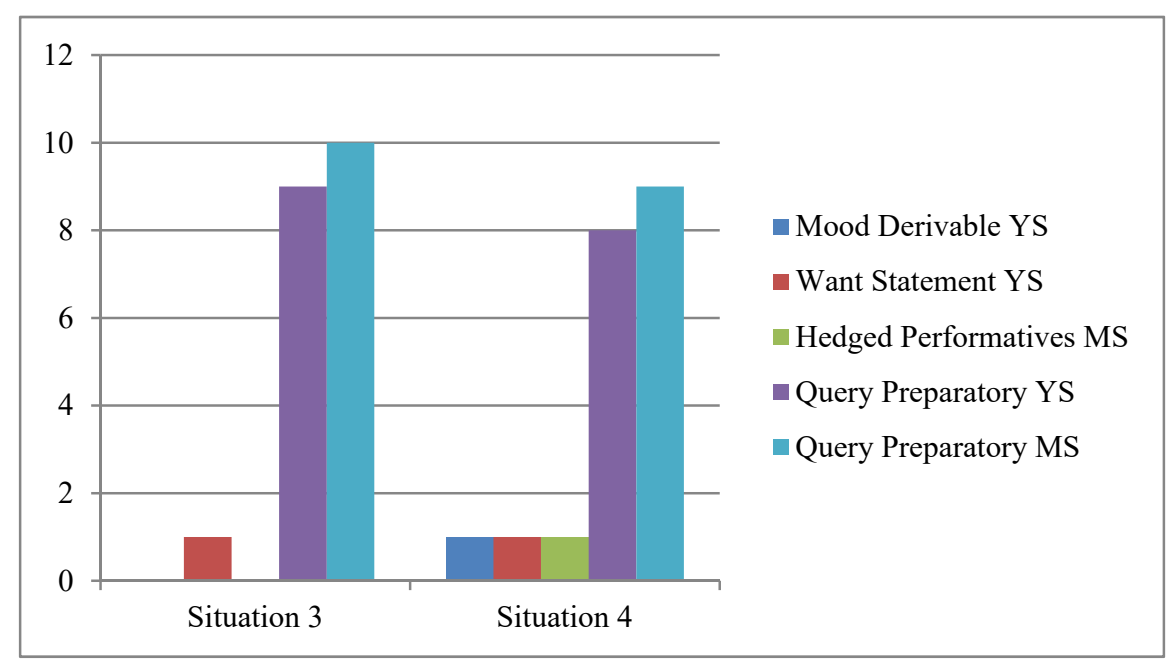

Figure 2. Distribution of request strategies used by Yemeni and Malay Students in situation 3 and 4

As it is shown in Table 3 and Figure 2, Yemeni students used 10\% direct strategies in the form of want statement and $90 \%$ query preparatory in situation 3 . On the other side, Malay students used $100 \%$ conventionally indirect strategies by means of query preparatory in the same situation.

In situation 4, Yemeni students used 10\% want statement and 10\% mood derivable, forms of direct strategies, and $80 \%$ conventionally indirect strategies in the form of query preparatory. On the other side, Malay students used $10 \%$ direct strategies in the form of hedged performatives, and $90 \%$ conventionally indirect strategies in the form of query preparatory.

Examples of direct strategies (want statement and mood derivable) used by Yemeni students:

I want you to write me a recommendation letter please.

I am so sorry teacher but I need your book to do my assignment.

Please, write me a recommendation letter.

Example of direct strategies (hedged performatives) used by Malay students:

I would like to ask you, if there is no trouble at all, to please write a recommendation letter for me.

Examples of conventionally indirect strategies (query preparatory) used by Yemeni students:

Teacher, may I borrow your book to help me with my assignment?

Teacher, may I have your book to do my assignment please?

Dear teacher, would you please write me a recommendation letter as I have got a scholarship?

Examples of conventionally indirect strategies (query preparatory) used by Malay students:

Sir, may I borrow your book to use as a reference in my assignment?

$\mathrm{Mr}$, can you lend me your book so I can do my assignment?

My dear teacher, would you please write a recommendation letter for me?

Sir, can you please write me a recommendation letter?

Situation 3 and 4 are classified under Scollon and Scollon's (1995) deference politeness system. In this system, the speaker does not have power (-Power) but there is a high social distance (+SD) between the speaker and the 
hearer. In such situations when the requestee is in a higher social position than the requester, it is better to use indirect strategies or direct strategies with softeners to show a sense of respect to the hearer. Using such strategies also help to smooth the interaction and negotiate the request with the hearer.

As shown in Table 3 and Figure 2 as well as the examples, it is clear that Yemeni and Malay students are aware of the social distance between them and the hearer who is their teacher in these two situations. So, they used conventionally indirect strategies most of the time to avoid losing face. Also, when they use direct strategies, they try to employ softeners to show their respect to the hearer. Yemeni students used formulaic ritualized expressions and apologies to show their respect when they used indirect strategies such as "please" and "I am sorry". Similarly, Malay students used expressions to mitigate the request when they use direct strategies like "if there is no trouble at all". Moreover, the use of softeners appeared also with the indirect strategies from both sides Yemeni and Malay students. For examples, Yemeni students used expressions to mitigate the request and show a sense of respect of teacher such as "teacher" and "dear teacher". Similarly, Malay students used formulaic ritualized expressions to show respect due to the social distance between them and the hearer such as "sir", "Mr" and "my dear teacher".

In addition, Yemeni and Malay students used semi-formulaic expressions such as "may", "can" and "would" to make their request indirect and show respect to the hearer.

It is clear from Table 3 and Figure 2 that both Yemeni and Malay students prefer to use indirect request strategies when there is a social distance between the speaker and the hearer. They use indirect request strategies as well as softeners with both direct and indirect request strategies to mitigate the request and show their respect to the hearer.

\section{Situation 5 and situation 6}

Situation 5: You want your neighbour to drive you to the market because your car has broken and you want to buy some fruit for your family. What would you say?

Situation 6: You went with your friend to the bookshop to buy some books, but you forgot your wallet at your home, so you want to borrow some money from your friend. What would you say?

The types of request strategies used by Yemeni and Malay students across situation 5 and 6 are shown in Table 4 and Figure 3.

Table 4. shows the frequency of request strategies used by Yemeni and Malay students in situation 5 and situation 6

\begin{tabular}{ccccc}
\hline \multirow{2}{*}{ Situation } & \multicolumn{2}{c}{ Direct Strategies } & \multicolumn{2}{c}{ Conventionally Indirect Strategies } \\
\cline { 2 - 5 } & Yemeni Students & Malay Students & Yemeni Students & Malay Students \\
\cline { 2 - 5 } & Mood Derivable & Want Statement & Query Preparatory & Query Preparatory \\
\hline S5 & & $10 \%$ & $100 \%$ & $90 \%$ \\
S6 & $10 \%$ & & $90 \%$ & $100 \%$ \\
\hline
\end{tabular}

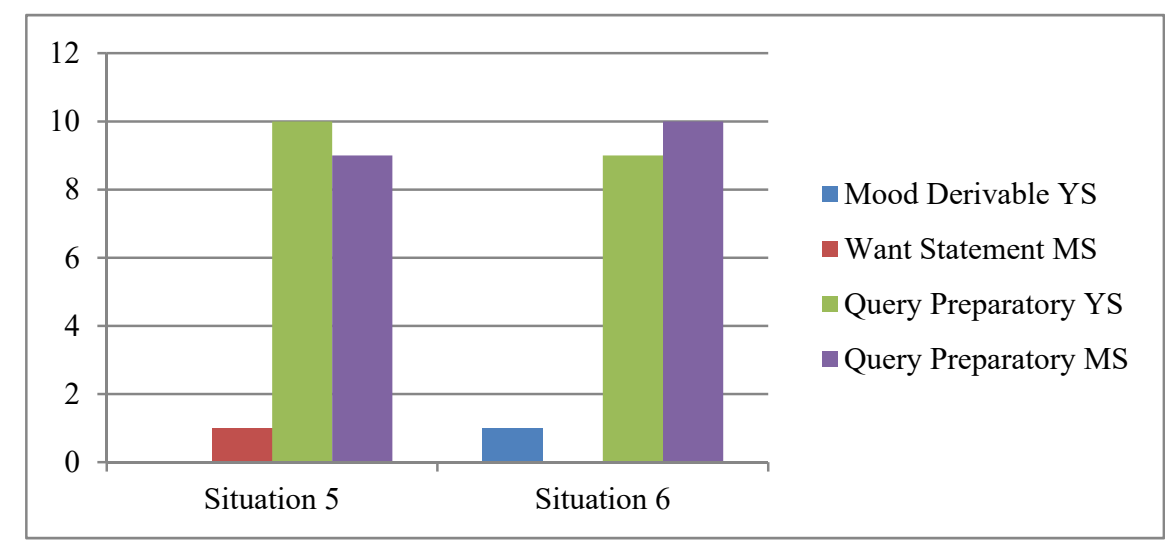

Figure 3. Distribution of request strategies used by Yemeni and Malay Students in situation 5 and 6

As it is shown in Table 4 and Figure 3, Yemeni students used 100\% conventionally indirect strategies in the form of query preparatory in situation 5. On the other side, Malay students used $10 \%$ direct strategies in the form of want statement in situation 5 . They also used $90 \%$ conventionally indirect strategies in the form of query 
preparatory.

In situation 6, Yemeni students used $10 \%$ direct strategies in the form of mood derivable and $90 \%$ conventionally indirect strategies in the form of query preparatory. In terms of Malay students, they used $100 \%$ conventionally indirect strategies in the form of query preparatory.

Example of direct strategies (mood derivable) employed by Yemeni students:

Lend some money to buy the books because I forget my wallet. I will give you the money when I get home.

Examples of direct strategies (want statement) employed by Malay students:

I need to go to the market to buy some fruits for my family.

Examples of conventionally indirect strategies (query preparatory) employed by Yemeni students:

Please sir, can I get a ride to the market. My car is broken down.

Excuse me, would you mind if you could drive me to the market?

May I borrow some money because I forget my wallet at home?

Sorry brother, can I get some money? I will give it back to you later.

Examples of conventionally indirect strategies (query preparatory) employed by Malay students:

I am so sorry to disturb you, by may you please drive me to the super market?

Excuse me neighbour, can you drive me to the market because my car is broken down and I need to buy some fruits for my family.

Hamza, will you please be kind and lend me some money because I left my money at home without noticing.

I am so sorry to ask you this, but may you please pay for my books? I promise to pay you back when I get home.

According to Scollon and Scollon (1995), situation 5 and 6 are classified under solidarity politeness system in which no one of the interlocutors has power over the other (-Power) and there is no social distance (-SD) between the interlocutors as they have equal social position.

Table 4 and Figure 3 show that both Yemeni and Malay students prefer to use query preparatory which is one of the conventionally indirect strategies. They try to make their request polite as much as possible even if there is no power or social distance existing between the interlocutors.

The examples mentioned above show that both Yemeni and Malay students used different types of formulaic expressions to show respect to the hearer and to mitigate the request. Yemenis students used terms of address such as "please sir" and "brother", and apologies such as "excuse me" and "sorry brother" in order to show respect to the hearer. Similarly, Malay students used ritualized formulaic expressions in order to show respect to the hearer when they make a request. Malay students use apologies such as "I am so sorry" and "excuse me". Also, they use terms of address like "neighbour" or terms of address including the first name as "Hamza".

In addition, both Yemeni and Malay students used semi-formulaic expressions to make their request indirect and to show a sense of respect to the hearer. Semi-formulaic expressions like "can", "could", "may", and "would" are used by both groups when they form query preparatory request strategies.

From the analysis of situation 5 and 6, it is clear that there is no difference between Yemeni and Malay students when they make requests as both mainly use conventionally indirect strategies by means of query preparatory. Also, they rarely use direct strategies when there is no power (-Power) or social distance (-SD) existing between the interlocutors. When they use direct strategies such as want statement or mood derivable, they often use softeners to mitigate the request and show respect to the hearer.

\section{Conclusion}

The aim of this study was to compare the request strategies employed by Yemeni and Malay secondary school students and to investigate if the social power and social distance have an effect on the students' choice of the request strategies. It used a pragmatic point of view in order to organize the strategies used for the purpose of making request. The data was collected through a Discourse Completion Test (DCT) which contains 6 situations and the students wrote their response in English language. The analysis depends on Blum-Kulk's et al. (1989) model which divides the request into head acts: direct request strategies, conventionally indirect request strategies, and non-conventionally indirect request strategies. Also, the situations were divided into three groups 
according to Scollon and Scollon's (1995) model which takes into consideration the power and social distance between the interlocutors. The first two situations are classified under the hierarchal politeness system in which the speaker has a power (+Power) over the hearer but there is no social distance (-SD) between the interlocutors. The next two situations, situation 3 and 4, are classified under the deference politeness system in which there is no power (-Power) existing between the interlocutors but there is a social distance (+SD). The last two situations, situation 5 and 6, are classified under the solidarity politeness system in which there is no power (-Power) or social distance (-SD) existing between the interlocutors.

The result of the analysis shows that there is a slight difference in the second situation between Yemeni and Malay students when they make requests in English language as Yemeni students used direct strategies more than the Malay students. However, Yemeni students used conventionally direct strategies by means of query preparatory more than the direct strategies. Generally, both groups prefer to use conventionally indirect strategies in the form of query preparatory.

In situations 1, 3, 4, 5 and 6-, there is no difference between Yemeni and Malay students as they prefer to use conventionally indirect strategies by means of query preparatory. In addition, both groups rarely use direct strategies and they often use softeners with direct strategies to show respect to the hearer and to mitigate the request. They also use softeners or formulaic ritualized expressions to soften the request even if they use conventionally indirect strategies.

It is clear that Yemeni and Malay secondary school students used conventionally indirect strategy and this method is considered the universal method of making request (Ellis, 1994; Trosborg, 1995).

The participants of this study are Yemeni EFL and Malay ESL secondary school students and it is clear that English is considered a foreign language for both groups. The findings of this study show that both groups use the common request strategies taught in the school but there is not sufficient sociopragmatic competence to make the students sensitive to social distance and social power because they use the same strategies when they interact with any person with or without the existence of social power and social distance between the interlocutors. The result of the studies which are conducted among native speakers and non-native speakers might be different. Thus, even if the students are aware of social power and social distance when making request in the mother tongue, they might not be aware of these sociopragmatic differences when they use L2 (Jalilifar, 2009).

\section{Acknowledgements}

We would like to express our gratitude and acknowledge the funder of the research and publication: DCP-2017-016/2 Empowering B40 Through 4IR Technology Applications, Universiti Kebangsaan Malaysia.

\section{References}

Alaoui, S. M. (2011). Politeness principle: A comparative study of English and Moroccan Arabic requests, offers and thanks. European Journal of Social Sciences, 20(1), 7-15.

Alfattah, M. H. A., \& Ravindranath, B. K. (2009). Politeness strategies in the English interlanguage requests of Yemeni learners. Iranian Journal of Language Studies (IJLS), 3(3), 249-266.

Al-Kahtani, S. A. W. (2005). Refusals realizations in three different cultures: A speech act theoretically-based cross-cultural study. Journal of King Saud University, 18, 35-57.

Al-Marrani, Y. M. A., \& Sazalie, A. (2010a). Polite request strategies by male speakers of Yemeni Arabic in male-male interaction and male-female interaction. The International Journal of Language Society and Culture, 63.

Al-Marrani, Y. M. A., \& Sazalie, A. B. (2010b). Polite request strategies by Yemeni females: A sociopragmatic study. Modern Journal of Applied Linguistics, 2, 478-516.

Aubed, M. M. (2012). Polite Requests in English and Arabic: A Comparative Study. Theory and Practice in Language Studies, 2(5), 916-922. https://doi.org/10.4304/tpls.2.5.916-922

BALCI, B. (2009). A Comparative Study on the Performance of Requests and Apologies by Turkish and American Teenagers: A Pragmatic Competence Point of View (Unpublished MA thesis). University of Cukurova.

Blum-Kulka, S. et al. (1989). Cross cultural pragmatics: Requests and apologies. Norwood, New Jersey. Ablex.

Blum-Kulka, S., \& Olshtain, E. (1984). Requests and Apologies: A Cross-Cultural Study of Speech Act Realization Patterns (CCSARP). Applied linguistics, 5(3), 196-213. https://doi.org/10.1093/applin/5.3.196

Brown, P., \& Levinson, S. (1987). Politeness: Some universals in language use. Cambridge: Cambridge 
University Press. https://doi.org/10.1017/CBO9780511813085

Byon, A. S. (2004). Sociopragmatic analysis of Korean requests: Pedagogical settings. Journal of Pragmatics, 36(9), 1673-1704. https://doi.org/10.1016/j.pragma.2004.05.003

Codreanu, A., \& Debu, A. (2011). Politeness in requests: Some research findings relevant for intercultural encounters. Journal of Defense Resources Management (JoDRM), (2), 127-136.

Daskalovska, N., Ivanovska, B., Kusevska, M., \& Ulanska, T. (2016). The Use of Request Strategies by EFL Learners. Procedia-Social and Behavioral Sciences, 232, 55-61. https://doi.org/10.1016/j.sbspro.2016.10.015

Ellis, R. (1994). The study of second language acquisition. Oxford University.

Elsayed, M. A. (2014). A Cross-cultural Study of Pragmatically Requestive Speech Act Realization Patterns. (Unpublished MA thesis). British University in Dubai.

Félix-Brasdefer, J. C. (2005). Indirectness and politeness in Mexican requests. In Selected proceedings of the 7th Hispanic Linguistics Symposium (Vol. 6678).

Jalilifar, A. (2009). Request strategies: Cross-sectional study of Iranian EFL learners and Australian native speakers. English Language Teaching, 2(1), 46. https://doi.org/10.5539/elt.v2n1p46

Kahraman, B., \& Akkuş, D. (2007). The use of request expressions by Turkish learners of Japanese. Journal of Theory \& Practice in Education (JTPE), 3(1).

Khalib, F. M., \& Tayeh, A. (2014). Indirectness in English requests among Malay university students. Procedia-Social and Behavioral Sciences, 134, 44-52. https://doi.org/10.1016/j.sbspro.2014.04.223

Lee, Y. (2011). Comparison of politeness and acceptability perceptions of request strategies between Chinese learners of English and native English speakers. International Journal of Language Studies, 5(3), 27-44. https://doi.org/10.5539/ass.v7n8p21

Marazita, L. R. A. (2009). The role of negative politeness in request: The strategies that non-native speakers apply and fail to apply when performing request. Journal of NELTA, 14(1), 82-90.

Nisa, A. A. K., \& Ariyanti, L. (2014). Request Strategies of Children Character in Diary of A Wimpy Kid Movie. Litera Kultura, 2(2).

Pinto, D., \& Raschio, R. (2007). A comparative study of requests in heritage speaker Spanish, L1 Spanish, and L1 English. International Journal of Bilingualism, 11(2), 135-155. https://doi.org/10.1177/13670069070110020101

Sattar, H. Q., Lah, S. C., \& Suleiman, R. R. R. (2009). Iraqi postgraduates' production and perception of requests: A pilot study. International Journal of Language, Society and Culture, 29, 56-70.

Scollon, R., \& Scollon, S. W. (2001). Intercultural Communication: A Discourse Approach (2nd ed.). Malden, MA: Blackwell.

Tabar, M. S. (2012). Cross-Cultural Speech Act Realization: The Case of Requests in the Persian and Turkish Speech of Iranian Speakers. International Journal of Business and Social Sciences, 3(13), 237-243.

Tabar, M. S., \& Malek, L. A. (2013). Delving into speech act of requests of Iranian Turkish informants. Procedia-Social and Behavioral Sciences, 70, 1724-1731. https://doi.org/10.1016/j.sbspro.2013.01.247

Tawalbeh, A., \& Al-Oqaily, E. (2012). In-directness and Politeness in American English and Saudi Arabic Requests: A cross-cultural comparison. Asian Social Science, 8(10), 85-98. https://doi.org/10.5539/ass.v8n10p85

Trosborg, A. (1995). Interlanguage pragmatics: Requests, complaints, and apologies (Vol.7). Walter de Gruyter. https://doi.org/10.1515/9783110885286

Youssef, A. M. S. (2012). Study of request strategies employed By Libyan and Malay Postgraduate Students at USM. International Journal of Learning and Development, 2(2), 144. https://doi.org/10.5296/ijld.v2i2.1631

\section{Copyrights}

Copyright for this article is retained by the author(s), with first publication rights granted to the journal.

This is an open-access article distributed under the terms and conditions of the Creative Commons Attribution license (http://creativecommons.org/licenses/by/4.0/). 